\title{
Analisa proses produksi part number D574-50081-201 menggunakan mesin milling CNC di PT DI
}

\author{
Eko Budiyanto ${ }^{1 *}$, Lukito Dwi Yuono ${ }^{2}$, Fatku Rohman ${ }^{3}$ \\ ${ }^{1,2,3}$ Prodi Teknik Mesin, Fakultas Teknik, Universitas Muhammadiyah Metro \\ JI. Ki Hajar Dewantara 15 A Kota Metro, Lampung, Indonesia \\ ${ }^{*}$ Corresponding author: eko_budiyanto99@yahoo.com
}

\begin{abstract}
The world of manufacturing technology is currently developing rapidly. Computerization carried out on manufacturing equipment makes it very easy for an industry, especially industries with a large production scale or mass production with a high number of orders in a short time. Manufacturing technology for machine tools usually uses a CNC (Computer Numeric Control) machine. Where the operation of this machine uses a program controlled by a computer and the programmer. This machine can produce products with high accuracy, even for very complicated manufacturing work. Product errors due to operator negligence can be reduced, as contact between the operator and the machine is minimal. However, if there is an error in the material or improper feed, the operator tends not to know because everything has been executed with the program that has been made. The aim of this research is to calculate the machining efficiency of the production process part number D57450081-201 using a CNC milling machine. Observations were made at the 3 axis prismatic machine section, PT. Dirgantara Indonesia (DI). The milling machine used was the QUASER MV 185 type machine. Part material used in this study was Aluminum alloy 7010. The results of observations and calculations obtained that the average machining efficiency was $13 \%$.
\end{abstract}

Keywords: CNC, production process, efficiency.

\section{Abstrak}

Perkembangan dunia teknologi manufaktur saat ini berkembang dengan pesat. Komputerisasi yang dilakukan pada alat-alat manufaktur sangatlah memudahkan suatu industri, terutama industri dengan skala produksi yang besar atau produksi masal dengan jumlah pesanan yang tinggi dalam waktu yang singkat. Teknologi manufaktur mesin-mesin perkakas biasanya menggunakan mesin CNC (Computer Numeric Control). Dimana pengoperasian mesin ini menggunakan program yang dikontrol dengan computer dan pemrogramnya. Mesin ini dapat menghasilkan produk dengan ketelitian yang tinggi, bahkan untuk pengerjaan manufaktur yang sangat rumit sekalipun. Kesalahan produk karena kelalaian operator dapat dikurangi, karena kontak antara operator dan mesin sangat sedikit. Namun, jika terjadi kesalahan pada material atau gerak makan yang tidak sesuai, operator cenderung tidak mengetahui karena semua sudah dijalankan dengan program yang sudah dibuat. Tujuan utama dari penelitian ini adalah untuk menghitung efisiensi pemesinan proses produksi part number D574-50081-201 menggunakan mesin milling CNC. Pengamatan dilakukan di bagian 3 axis prismatic machine, PT. Dirgantara Indonesia (DI). Mesin frais yang digunakan adalah mesin tipe QUASER MV 185. Material part yang digunakan pada penelitian ini adalah Aluminium alloy 7010. Hasil pengamatan dan perhitungan diperoleh efisiensi rata-rata pemesinan sebesar sebesar $13 \%$.

Kata kunci: CNC, proses produksi, efisiensi.

\section{Pendahuluan}

Indonesia mempunyai industri pesawat terbang terbang yang bernama PT.
Dirgantara Indonesia, yang menjadi andalan industri pesawat terbang nusantara. Produk andalannya adalah $\mathrm{N} 290$, dan 219, nama N 
sendiri diambil dari nama seorang tokoh yang meninggal saat uji terbang pesawat buatan Indonesia dengan nama Noertanio. Selain memproduksi pesawat tebang PT. DI juga memproduksi suku cadang untuk pesawat konvesional lainnya [1].

Perkembangan dunia teknologi manufaktur saat ini berkembang dengan pesat [2]. Komputerisasi yang dilakukan pada alat-alat manufaktur sangatlah memudahkan suatu industri, terutama industri dengan skala produksi yang besar atau produksi masal dengan jumlah pesanan yang tinggi dalam waktu yang singkat. Dengan menggunakan computer sebagai alat bantu produksi, maka suatu industri dapat melakukan proses produksi secara cepat dan hasilnya dapat dipertanggung jawabkan baik dari segi kehalusan, keseragaman bentuk maupun ukuran yang diinginkan [3].

Penggunaan teknologi ini dapat menekan biaya produksi secara keseluruhan, meskipun dalam segi konsumsi energi yang dibutuhkan cukup besar. Hal itu terjadi karena jumlah pekerja yang dibutuhkan jauh lebih sedikit dan waktu yang dibutuhkan dapat diminimalkan sehingga dalam waktu yang singkat dan jumlah pekerja yang sedikit dapat mmenghasilkan produksi yang banyak dangan kualitas yang baik.

Teknologi manufaktur mesin-mesin perkakas biasanya menggunakan mesin CNC (Computer Numeric Control) [4]. Dimana pengoperasian mesin ini menggunakan program yang dikontrol dengan computer dan pemrogramnya. Mesin ini dapat menghasilkan produk dengan ketelitian yang tinggi, bahkan untuk pengerjaan manufaktur yang sangat rumit sekalipun. Kesalahan produk karena kelalaian operator dapat dikurangi, karena kontak antara operator dan mesin sangat sedikit [5].

Jika terjadi kesalahan pada material atau gerak makan yang tidak sesuai, operator cenderung tidak mengetahui karena semua sudah dijalankan dengan program yang sudah dibuat. Operator hanya dapat mengetaui dengan cara melepas dan memeriksa material lebih lanjut. Sedangkan untuk kesalahan yang terjadi karena pahat yang dipakai tidak sesuai atau tumpul dan pemakanan yang terlalu besar, operator dapat mengetahuinya lewat suara gesekan dan getaran yang yang dihasilkan oleh mesin yang cukup besar dan menggangu pendengaran. Hal tersebut sangat merugikan karena harga material yang rusak dan lebih fatal lagi jika pahat yang digunakan mengalami patah.

Karena biaya produksi yang sangat mahal maka kesempurnaan atas produk sangatlah menjadi prioritas yang harus dicapai [6]. Jika terjadi kesalahan sedikit saja maka produk yang dihasilkan tidak dapat dipakai dan hanya akan menjadi sampah yang tidak ada harganya. Kesalahan pada produk dapat dipengaruhi dari berbagai pihak. Seperti kesalahan program yang dibuat, biasanya dari penggunaan perhitungan yang tidak sesuai dimensinya yang kurang akurat dan tahap pemakanan yang kurang sesuai. Untuk operator biasanya hanya kesalahan membaca gambar, kelalaian memeriksa pahat yang dipakai dan tidak ratanya pemasangan benda kerja [7].

Setiap langkah pekerjaan yang dilakukan harus melalui proses perhitungan dan analisa perhitungan yang tepat agar hasil yang dicapai memuaskan dan tidak terjadi kesalahan baik dalam penggunaan pahat, kecepataan makan dan lain-lain. Dengan memperhitungkan waktu produksi yang semaksimal mungkin.

\section{Tinjauan Pustaka}

\section{Mesin milling CNC}

Mesin milling atau mesin frais adalah mesin yang paling mampu melakukan banyak tugas bila dibandingkan dengan mesin perkakas yang lain. Hal ini disebabkan karena selain mampu memesin permukaan datar maupun berlekuk dengan penyelesaian dan ketelitian istimewa, juga berguna untuk menghaluskan atau meratakan benda kerja sesuai dengan dimensi yang dikehendaki. Proses frais adalah proses yang menghasilkan chips 
(geram). Frais menghasilkan permukaan yang datar atau berbentuk profil pada ukuran yang ditentukan dan kehalusan atau kualitas permukaan yang ditentukan [8].

Prinsip kerja mesin milling adalah tenaga untuk pemotongan yang berasal dari energi listrik diubah menjadi gerak utama oleh sebuah motor listrik, selanjutnya gerakan utama tersebut akan diteruskan melalui suatu transmisi untuk menghasilkan gerakan putar pada spindel mesin milling.

Pengerjaan yang biasa dilakukan pada mesin terdiri dari pengefraisan sisi dimana pisau sejajar dengan permukaan benda kerja, dan pegefraisan muka dimana sumbu pisau tegak lurus dengan permukaan benda kerja.

Beberapa metode dalam mesin frais terdiri dari climb mill dan conventional milling. Climb mill merupakan cara pengefraisan dimana putaran cutter searah dengan gerakan benda kerja. Gaya potong menarik benda kerja ke dalam cutter sehingga faktor kerusakan pahat akan lebih besar. Hanya mesin yang mempunyai alat pengukur keregangan diperbolehkan memakai metode pemotongan ini. Sedangkan conventional milling merupakan pengefraisan dimana putaran cutter berlawanan arah dengan gerakan benda kerja, pemotongan ini dimulai dengan beram yang tipis dan metode ini digunakan untuk semua jenis mesin milling [9].

\section{Elemen dasar proses milling}

1. Kecepatan potong

Kecepatan potong alat potong mesin frais adalah jarak yang ditempuh oleh mata potong (tool) dalam satuan menit, dirumuskan [10]:

$$
v=\frac{\pi \cdot n \cdot d}{1000}
$$

Dengan, $\quad \mathrm{v}=$ Kecepatan potong $(\mathrm{m} / \mathrm{min})$

$$
\begin{aligned}
& \mathrm{n}=\text { Putaran spindel }(\mathrm{rpm}) \\
& \mathrm{d}=\text { Diameter tool }(\mathrm{mm})
\end{aligned}
$$

2. Kecepatan makan

Gerak makan merupakan gerak dari setiap gigi pemotong, gerak ini dapat dikonversikan ke dalam kecepatan makan dengan memperhitungkan kecepatan spindel dan jumlah pemotong atau gigi.
Untuk kecepatan makan dirumuskan [10]:

$$
v_{f}=f_{z} \cdot z \cdot n
$$

Dengan, $v_{f}=$ kecepatan makan $(\mathrm{mm} / \mathrm{min})$

$\mathrm{f}_{\mathrm{z}}=$ Gerak makan pergigi $(\mathrm{mm} /$ gigi $)$

$\mathrm{z}=$ banyak gigi

3. Waktu pemotongan

Adalah waktu yang dibutuhkan untuk melakukan pemakanan benda kerja menjadi yang diinginkan [10].

$$
t_{c}=\frac{l_{t}}{f}
$$

Dengan, $t_{c}=$ Waktu pemotongan $(\min )$

$\mathrm{L}_{\mathrm{t}}=$ Panjang permesinan $(\mathrm{mm})$

4. Kecepatan penghasilan geram

Kecepatan pelepasan material atau penghasilan geram dalam proses frais merupakan perkalian antara luas bidang melintang dari pemotongan dengan kecepatan makan [10].

$$
Z=\frac{v \cdot a \cdot w}{1000}
$$

Dengan, $Z=$ Kecepatan penghasilan geram $\left(\mathrm{cm}^{3} / \mathrm{min}\right)$

$\mathrm{a}=$ Kedalaman pemotongan $(\mathrm{mm})$

$\mathrm{w}=$ lebar pemakanan $(\mathrm{mm})$

a. Untuk proses pengeboran digunakan rumus [10]:

$$
Z=\frac{v_{f} \cdot \pi \cdot d^{2}}{4.1000}
$$

$\frac{\pi \cdot d^{2}}{4}=$ luas penampang senter drill $(\mathrm{mm})$

b. Dan untuk ball nose digunakan rumus [10]:

Dengan,

$$
Z=\frac{v_{f} \cdot\left(l_{\alpha}-l_{s}\right)}{1000}
$$

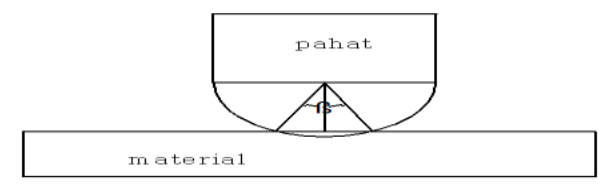

Gambar 1. Ilustrasi pemakanan pahat [11]

$l_{\text {tembereng }}=l_{\beta}-l_{\Delta}[11]$

Dengan,

$$
\begin{aligned}
& l_{\beta}=\beta / 360 \cdot \pi \cdot r^{2} \\
& l_{\Delta}=\frac{\text { alas xting i }}{2}
\end{aligned}
$$

5. Gaya potong dan momen puntir proses frais

Gaya potong untuk setiap gigi akan berfluktuasi mengikuti perubahan sudut 
posisi gigi. Karena tebal geram tersebut berubah selama proses pemotongan berlangsung maka dipilih tebal geram ratarata, atas mana gaya potong spesifik ditentukan. [10]:

Gaya potong tangensial $\mathrm{F}_{\mathrm{t}}$ ditentukan

Dengan,

$$
\begin{gathered}
F_{t}=A \cdot k_{1}, \text { maka } \\
F_{t m}=A_{m} \cdot k_{s m}
\end{gathered}
$$

$F_{t m}=$ Gaya potong pergigi rata-rata $(\mathrm{N})$

$A_{m}=$ Penampang geram sebelum terpotong rata-rata $\left(\mathrm{mm}^{2}\right)$

$\mathrm{A}_{\mathrm{m}}=\mathrm{b} . \mathrm{h}_{\mathrm{m}}$

$k_{s m}=$ Gaya potong spesifik rata-rata $\left(\mathrm{N} / \mathrm{mm}^{2}\right)$

a. Tebal geram rata - rata

$$
\begin{array}{r}
f_{\text {zrata }^{2}}=\sin K_{r} \cdot \frac{360}{\pi} \cdot \frac{f_{z} \cdot w}{\varphi \cdot d}[11] \\
\cos \varphi=\frac{d / 2-a r}{d / 2}
\end{array}
$$

Dengan, $K_{r}=$ Entering angel

$$
\begin{aligned}
& f_{\text {r rata }^{2}}=\underset{(\mathrm{mm})}{\text { Tebal }} \text { geram rata-rata } \\
& \varphi=\text { Sudut geser }\left({ }^{0}\right)
\end{aligned}
$$

b. Gaya potong spesifik rata-rata [10]

$$
\begin{gathered}
K_{s m}=\frac{2 \cdot \pi \cdot n \cdot M_{t m}}{w \cdot a \cdot v_{f}} \\
M_{t m}=C_{1} \cdot d^{x} \cdot f^{y}
\end{gathered}
$$

Dengan, $K_{s m}=$ Gaya potong spesifik ratarata $\left(\mathrm{N} / \mathrm{mm}^{2}\right)$

$M_{t m}=$ Momen puntir rata-rata $(\mathrm{N} \mathrm{mm})$

$C_{1}=$ Konstanta material

c. Gaya tekan

Karena titik mula setiap pahat berbeda-beda, maka harus diperhitungkan gaya tekan yang terjadi pada awal pemakanan untuk mencapai dept of cut yang diinginkan [10].

$$
F=C_{2} \cdot d^{m} \cdot f^{n}
$$

Dengan, $F=$ Gaya tekan yang terjadi saat pemakanan $(\mathrm{N})$

$\mathrm{m}, \mathrm{n}=$ Pangkat untk diameter dan gerak makan dalam rumus korelasi momen dan gaya (tabel) d. Gaya potong spesifik pada senter drill dapat didefinisikan sebagai berikut [10]: (pengeboran atau penggurdian)

$$
\begin{aligned}
k_{d} & =\frac{8 . M_{t}}{d^{2} . f} \\
A & =\frac{d . f}{4}
\end{aligned}
$$

e. Gaya tangensial pada mata potong [10] (pengeboran/ penggurdian)

$$
k_{d}=\frac{F_{t}}{A}
$$

Dengan, $F_{t}=$ Gaya tangensial pada mata potong $(\mathrm{N})$

$\mathrm{A}=$ luas penampang geram $\left(\mathrm{mm}^{2}\right)$

Tabel 1. Data pemesinan [10]

\begin{tabular}{cccccc}
\hline $\begin{array}{c}\text { Benda kerja } \\
(\mathrm{SAE}-\mathrm{DIN})\end{array}$ & $\begin{array}{c}\mathrm{C}_{1} \\
(\mathrm{~N} / \mathrm{mm})\end{array}$ & $\mathrm{x}$ & $\mathrm{y}$ & $\mathrm{K}_{\mathrm{d} 1.1}$ & $\mathrm{~K}_{\mathrm{d} 5.1}$ \\
\hline Baja & & & & & \\
$(1020-\mathrm{C} 22)$ & 563 & 1,8 & 0,78 & 4288 & 3259 \\
\hline$(1035-\mathrm{C} 35)$ & 620 & 1,8 & 0,78 & 4960 & 3770 \\
\hline$(1112-9 \mathrm{~S} 20)$ & 410 & 1,8 & 0,78 & 3280 & 2493 \\
\hline$(3151-)$ & 741 & 1,8 & 0,78 & 5960 & 4530 \\
\hline Besi tuang & 300 & 1,7 & 0,60 & 2400 & 1602 \\
\hline Kuningan & 115 & 1,9 & 0,73 & 920 & 817 \\
\hline Aluminium & 131 & 1,9 & 0,83 & 1048 & 200 \\
\hline$C_{1}, C_{2}=$ Harga konstanta $(\mathrm{N} / \mathrm{mm})$ & yang diperoleh dari hasil \\
percobaan
\end{tabular}

f. Jadi gaya tangensial total pemotongan sebagai berikut [10]:

$$
F_{t m s}=F_{t m} . Z
$$

6. Daya pemotongan dan efisiensi pemesinan

Daya pemotongan dalam proses pembentukan geram ditentukan oleh gaya potongan dengan dengan kecepatan pemotongan atau momen puntir pada pada pahat dengan kecepatan putarannya. Maka daya pemotongan dapat dirumuskan [10]:

$$
N_{c t}=N_{c}+N_{f}
$$

a. Karena $\mathrm{N}_{\mathrm{f}}$, jauh lebil kecil dari pada $\mathrm{N}_{\mathrm{C}}$, maka nilai $\mathrm{N}_{\mathrm{f}}$ dapat diabaikan, sehingga daya total pada mesin frais dan gurdi adalah [10]:

$$
N_{c t}=N_{c r a t a}=\frac{M_{t r a t a} 2 . \pi \cdot n}{60 \times 10^{6}}
$$

Dengan, $N_{c t}=$ Daya pemotongan total $(\mathrm{kW})$

$$
\begin{aligned}
& N_{c}=\text { Daya potong }(\mathrm{kW}) \\
& N_{f}=\text { Daya makan }(\mathrm{kW})
\end{aligned}
$$

b. Daya pemotongan diatas adalah daya yang dipakai dalam proses pembentukan geram. Sehinga efisiensi pemesinan dapat didefinisikan sebagai berikut [10]:

$$
\eta_{c}=\frac{N_{c}}{N_{m c}} \times 100 \%
$$


Dengan, $\eta_{c}=$ efisiensi pemesinan $(\%)$

$N_{m c}=$ daya mesin yang tersedia $(\mathrm{kW})$

\section{Metode Penelitian}

Pengamatan dilakukan di bagian 3 axis prismatic machine, PT. Dirgantara Indonesia. Dengan hasil pengamatan sebagai berikut.

\section{Mesin milling $\mathrm{CNC}$ vertikal}

Mesin frais yang digunakan adalah mesin tipe QUASER MV 185 dengan spesifikasi tertera pada Tabel 2.

Tabel 2. Spesifikasi mesin

\begin{tabular}{|c|c|}
\hline Technical Data & MV184 \\
\hline $\begin{array}{l}\text { Work Range } \\
\text { Table size }(\mathrm{mm}) \\
\text { Spindle nose to table } \\
\text { surface }(\mathrm{mm}) \\
\text { Taable load capacity }(\mathrm{kg})\end{array}$ & $\begin{array}{c}1.020 \times 600 \\
1,0202 / 610 / 610 \\
100-710\end{array}$ \\
\hline $\begin{array}{l}\text { Feed Drive } \\
\text { Feed force } x / y / z(N) \\
\text { Rapid movement } x / y / z \\
(\mathrm{~m} / \mathrm{min}) \\
\text { Acceleration } x / y / z\left(m / s^{2}\right) \\
\text { Dia. Dan pitch of the boll } \\
\text { screw }\end{array}$ & $\begin{array}{c}6.283 / 6.283 / 17.671 \\
32 \\
3 / 3 / 3 \\
\varnothing 45 / \mathrm{P}=12 / 8\end{array}$ \\
\hline $\begin{array}{l}\text { Accuracy Position / } \\
\text { Repeatability } \\
\text { ISO 230-2 } \\
\text { JIS } 6338(300 \mathrm{~mm}) \\
\text { VDI } 3441\end{array}$ & $\begin{array}{c}0,002 \\
\pm 0,002 \\
0,004\end{array}$ \\
\hline $\begin{array}{l}\text { Main Spindle } \\
\text { Spindle model } \\
\text { Max. Spindle speed (rpm) } \\
\text { Spindle base speed } \\
\text { Spindle output kW (S6- } \\
40 \%) \\
\text { Spindle torque Nm (S6- } \\
40 \%) \\
\text { Spindle transmission } \\
\text { Spindle diameter (mm) }\end{array}$ & $\begin{array}{c}40 \text { taper } \\
10.000 \\
15.000 \\
15 \\
96 \\
\text { Coupling } \\
\varnothing 70\end{array}$ \\
\hline $\begin{array}{l}\text { Tool Changger } \\
\text { Tool selection } \\
\text { Magazine positions } \\
\text { Max. Tool diameter (mm) } \\
\text { Max. Tool dia, duo to } \\
\text { neighbor pots are empty } \\
\text { Max. Tool length (mm) } \\
\text { Max. Tool weigth (kg) } \\
\text { CTC time-ISO 10791-9 } \\
\text { (sec.)-60 Hz }\end{array}$ & $\begin{array}{c}\text { Random } \\
30 \\
76,2 \\
125 \\
280 \\
7 \\
4\end{array}$ \\
\hline $\begin{array}{l}\text { Coolan System } \\
\text { Coolant tank capacity (liter) } \\
\text { Pump capasity }\end{array}$ & 300 \\
\hline
\end{tabular}

\begin{tabular}{lc}
\hline $\begin{array}{l}\text { Nozzel coolant } \\
\text { Through spindel coolant }\end{array}$ & $601 / \mathrm{min} ., 3,5 \mathrm{bar}$ \\
Wash down & $601 / \mathrm{min} ., 3,5 \mathrm{bar}$ \\
\hline Machine Size & 2.860 \\
Height $(\mathrm{mm})$ & $2.100 / 2.600$ \\
Floor spece WxD (mm) & 6.300 \\
Weight $(\mathrm{kg})$ & \\
\hline Connections & $400 \mathrm{~V} / 50 \mathrm{~Hz}$ \\
Main power & 17,5 \\
Power consumpsion (KVA) & \\
\hline
\end{tabular}

Sumber : Quaser hand book

\section{Part number D574 - 50081 - 200 / 201}

Adalah part yang dipesan langsung oleh Airbus operation Ltd, dengan nama part Bracket. Material yang digunakan pada part ini adalah Aluminium alloy 7010 dengan komposisi kimia dan sifat mekaniknya dijelaskan pada Tabel 3.

Tabel 3. Komposisi kimia Aluminium alloy 7010

\begin{tabular}{lcccccccccc}
\hline $\begin{array}{l}\text { Unsur } \\
(\%)\end{array}$ & $\mathrm{Si}$ & $\mathrm{Fe}$ & $\mathrm{Cu}$ & $\mathrm{Mn}$ & $\mathrm{Mg}$ & $\mathrm{Cr}$ & $\mathrm{Zn}$ & $\mathrm{Ti}$ & $\mathrm{Zr}$ & $\mathrm{Al}$ \\
\hline Min & - & - & 1,5 & - & 2,1 & - & - & 5,7 & 0,1 & 90,6 \\
\hline Max & 0,12 & 0,15 & 2,0 & 0,1 & 2,6 & 0,05 & 6,7 & 0,06 & 0,16 & 88,06 \\
\hline
\end{tabular}

Sumber : Airbus operation

\section{Pahat (tool) dan waktu penggunaannya}

Tabel 4. Pahat dan penggunaannya

\begin{tabular}{cllc}
\hline No & \multicolumn{1}{c}{ Tool } & Bahan & $\begin{array}{c}\text { Waktu } \\
\text { (menit) }\end{array}$ \\
\hline 1 & $\begin{array}{l}\text { Slot drill short } \\
\text { diameter 25 mm } \\
\text { dengan jari-jari 0 }\end{array}$ & Carbide & 38 \\
\hline 2 & $\begin{array}{l}\text { Slot drill short } \\
\text { diameter 10 mm } \\
\text { dengan jari-jari 1 mm }\end{array}$ & Carbide & 12,30 \\
\hline 4 & $\begin{array}{l}\text { Slot drill short } \\
\text { diameter 10 mm } \\
\text { dengan jari-jari 0 }\end{array}$ & Carbide & 5 \\
\hline 5 & $\begin{array}{l}\text { Ball nose Slot drill } \\
\text { short diameter 12 mm }\end{array}$ & Carbide & 47,40 \\
\hline 6 & $\begin{array}{l}\text { Center drill diameter 2 } \\
\text { mm }\end{array}$ & Hss & 1 \\
\hline 7 & $\begin{array}{l}\text { Twist drill diameter } \\
11,8 \text { mm }\end{array}$ & Hss & 2,7 \\
\hline 8 & $\begin{array}{l}\text { Reammer machbe } \\
\text { diameter 12H7 }\end{array}$ & Carbide & 1 \\
\hline & Total waktu pemesinan & 108,17 \\
\hline
\end{tabular}

Sumber : Indonesia aerostuctur 
Tabel 5. Hasil perhitungan CCS (computer cutting data service)

\begin{tabular}{|c|c|c|c|c|c|c|c|c|c|}
\hline 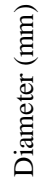 & 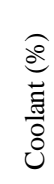 & $\begin{array}{l}\bar{E} \\
\underline{\Xi} \\
\frac{\partial}{\alpha}\end{array}$ & 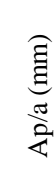 & 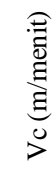 & $\underset{=}{\widehat{E}}$ & 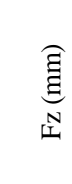 & 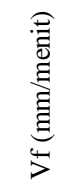 & 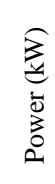 & 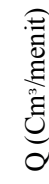 \\
\hline 25 & 10 & 12,5 & 2,22 & 589 & 7500 & 0,158 & 2372 & 0,9 & 65,8 \\
\hline 10 & 10 & 10 & 0,5 & 236 & 7500 & 0,1 & 1500 & 0,1 & 7,5 \\
\hline 12 & 10 & 12 & 1 & 283 & 7500 & 0,11 & 1643 & 0,3 & 19,7 \\
\hline 12 & 10 & 4,4 & 0,5 & 283 & 7500 & 0,11 & 1643 & 0,1 & 3,6 \\
\hline
\end{tabular}

Sumber : Tool service (ccs) PT. Dirgantara Indonesia

\section{Hasil dan Pembahasan}

Proses pemesinan termasuk dalam klasifikasi proses pemotongan logam, merupakan suatu proses yang digunakan untuk mengubah bentuk suatu produk dari logam (komponen mesin) dengan cara memotong, mengupas, atau memisah.

Diketahui putaran yang dihasilkan $10.000 \mathrm{rpm}$, untuk menjaga agar mesin tetap dalam performa yang maksimal dan memperpanjang umur pengoperasian maka dikalikan dengan faktor keamanan dengan harga $75 \%$ [12]. Jadi putaran yang dipakai $10.000 \mathrm{rpm} \times 75 \%=7500 \mathrm{rpm}$

Perhitungan dasar proses frais sebagai berikut :

\section{a. Kecepatan potong}

1). Slot drill short diameter $25 \mathrm{~mm}$ dengan jari-jari 0

$$
\begin{aligned}
v & =\frac{\pi \cdot d \cdot n}{1000}=\frac{3,14.25 \mathrm{~mm} .7500 \mathrm{rpm}}{1000} \\
& =588,75 \mathrm{~m} / \mathrm{min}
\end{aligned}
$$

Nilai ini dapat diterima karena batas maksimun untuk tool carbide dengan bahan yang dipotong Aluminium adalah $700 \mathrm{~m} / \min$ [12].

2). Slot drill short diameter $10 \mathrm{~mm}$ dengan jari-jari $1 \mathrm{~mm}$

$v=\frac{\pi \cdot d \cdot n}{1000}$

$v=\frac{3,14.10 \mathrm{~mm} .7500 \mathrm{rpm}}{1000}$

$v=235,5 \mathrm{~m} / \min$

Nilai ini dapat diterima karena batas maksimun untuk tool carbide dengan bahan yang dipotong Aluminium adalah $700 \mathrm{~m} / \min [12]$.
3). Ball nose Slot drill short diameter 12 $\mathrm{mm}$

$v=\frac{\pi \cdot d \cdot n}{1000}$

$v=\frac{3,14.12 \mathrm{~mm} .7500 \mathrm{rpm}}{1000}$

$v=282,6 \mathrm{~m} / \min$

Nilai ini dapat diterima karena batas maksimun untuk tool carbide dengan bahan yang dipotong Aluminium adalah $700 \mathrm{~m} / \min [12]$

4). Center drill diameter $2 \mathrm{~mm}$

Untuk tool dengan bahan HSS lebih mudah tumpul atau aus dengan kecepatan potong yang tinggi, untuk itu perlu diambil faktor koreksi sebesar $40 \%$ - $60 \%$ dari kecepan putar spindel [12].

Jadi kecepatan spindel yang dipakai sebesar $7500 \mathrm{rpn} \times 60 \%=4500 \mathrm{rpm}$

$v=\frac{\pi \cdot d \cdot n}{1000}$

$v=\frac{3,14.2 \mathrm{~mm} .4500 \mathrm{rpm}}{1000}$

$v=28,26 \mathrm{~m} / \min$

Nilai ini dapat diterima karena batas maksimun untuk tool HSS dengan bahan yang dipotong Aluminium adalah $100 \mathrm{~m} / \min$ [12].

5). Twist drill diameter $11,8 \mathrm{~mm}$

$v=\frac{\pi \cdot d \cdot n}{1000}$

$v=\frac{3,14.11,8 \mathrm{~mm} .4500 \mathrm{rpm}}{1000}$

$v=166,73 \mathrm{~m} / \min$

Nilai ini dapat diterima karena batas maksimun untuk tool HSS dengan bahan yang dipotong Aluminium adalah $100 \mathrm{~m} / \min$ [12]. Maka salah satu caranya untuk memperkecil kecepatan potong adalah dengan memperkecil putaran spindel. Jadi kecepatan potongnya adalah :

$100 \mathrm{~m} / \mathrm{min}=\frac{3,14.11,8 \mathrm{~mm} \cdot \mathrm{n}}{1000}$

$n=2700 \mathrm{rpm}$ dan kecepatan potongnya $100 \mathrm{~m} / \mathrm{min}$

6). Reammer machbe diameter $12 \mathrm{H} 7$

$v=\frac{\pi \cdot d \cdot n}{1000}$

$v=\frac{3,14.12 \mathrm{~mm} .7500 \mathrm{rpm}}{1000}$

$v=282,6^{\mathrm{m}} / \mathrm{min}$

Nilai ini dapat diterima karena batas maksimun untuk tool carbide dengan bahan 
yang dipotong Aluminium adalah $700 \mathrm{~m} / \min$ [12].

\section{b. Kecepatan makan}

Untuk nilai $f_{z}$ ditentukan dengan menggunakan tabel berdasarkan jumlah dari kandungan silikonnya dan diameter cutter (pahat).

1). Slot drill short diameter $25 \mathrm{~mm}$ dengan jari-jari 0

$v_{f}=f_{z} \cdot z \cdot n$

$v_{f}=0,165 \mathrm{~mm} / \mathrm{rad} \cdot 2.7500 \mathrm{rpm}$

$v_{f}=2475 \mathrm{~mm} / \mathrm{min}$

2). Slot drill short diameter $10 \mathrm{~mm}$ dengan jari-jari $1 \mathrm{~mm}$

$v_{f}=f_{z} \cdot z \cdot n$

$v_{f}=0,085 \mathrm{~mm} / \mathrm{rad} \cdot 2.7500 \mathrm{rpm}$

$v_{f}=1200 \mathrm{~mm} / \mathrm{min}$

3). Ball nose Slot drill short diameter 12 $\mathrm{mm}$

$v_{f}=f_{z} \cdot z \cdot n$

$v_{f}=0,09 \mathrm{~mm} / \mathrm{rad} \cdot 2.7500 \mathrm{rpm}$

$v_{f}=1350 \mathrm{~mm} / \mathrm{min}$

4). Center drill diameter $2 \mathrm{~mm}$

$v_{f}=f_{z} \cdot z \cdot n$

$v_{f}=0,015 \mathrm{~mm} / \mathrm{rad} \cdot 2.4500 \mathrm{rpm}$

$v_{f}=135 \mathrm{~mm} / \mathrm{min}$

5). Twist drill diameter $11,8 \mathrm{~mm}$

$v_{f}=f_{z} \cdot z \cdot n$

$v_{f}=0,062 \mathrm{~mm} / \mathrm{rad} \cdot 2.2700 \mathrm{rpm}$

$v_{f}=334,8 \mathrm{~mm} / \mathrm{min}$

6). Reammer machbe diameter $12 \mathrm{H} 7$

$v_{f}=f_{z} \cdot z \cdot n$

$v_{f}=0,09 \mathrm{~mm} / \mathrm{rad} .2 .7500 \mathrm{rpm}$

$v_{f}=1350 \mathrm{~mm} / \mathrm{min}$

c. Waktu pemotongan

1). Slot drill short diameter $25 \mathrm{~mm}$ dengan jari-jari 0

$t_{c}=\frac{l_{t}}{v_{f}}$

$l_{v} \geq \sqrt{a(d-a)}$

$l_{v} \geq \sqrt{2,22 \mathrm{~mm}(25 \mathrm{~mm}-2,22 \mathrm{~mm})}$

$l_{v} \geq 7.11 \mathrm{~mm}$

$l_{n}=\frac{d}{2}$

$l_{n}=12,5 \mathrm{~mm}$

$l_{t}=\left(l_{v}+l_{w}+l_{n}\right) \times \mathrm{L}$

$l_{t}=7.11 \mathrm{~mm}+250 \mathrm{~mm}+12,5 \mathrm{~mm}$ $l_{t}=(269,61 \mathrm{~mm}+$

$12,5 \mathrm{~mm}) x 28$ langkah

$l_{t}=7899,08 \mathrm{~mm}$

$t_{c}=\frac{7899,08 \mathrm{~mm}}{2475 \mathrm{~mm} / \mathrm{min}}$

$t_{c}=3$ menit 36 detik

2). Slot drill short diameter $10 \mathrm{~mm}$ dengan jari-jari $1 \mathrm{~mm}$

$t_{c}=\frac{l_{t}}{v_{f}}$

$l_{n}=\frac{d}{2}$

$l_{n}=5 \mathrm{~mm}$

$l_{t}=\left(l_{w}-l_{n}-l_{n}\right) \times \mathrm{L}$

$l_{t}=145 \mathrm{~m}-5 \mathrm{~mm}-5 \mathrm{~mm}$

Karena w 2x dan a 63x maka didapat asumsi panjang langkah total

$l_{t}=135 \mathrm{~mm} \times 126$ langkah

$l_{t}=17010 \mathrm{~mm}$

$t_{c}=\frac{17010 \mathrm{~mm}}{1200 \mathrm{~mm} / \mathrm{min}}$

$t_{c}=14$ menit 17 detik

Karena pahat Slot drill short diameter 10 $\mathrm{mm}$ dengan jari-jari $1 \mathrm{~mm}$ ini di gunakan dalam 2 tahap maka 14,17 $\mathrm{mm}$ x $2=28$ menit 34 detik

3). Ball nose Slot drill short diameter 12 $\mathrm{mm}$

$t_{c}=\frac{l_{t}}{v_{f}}$

$l_{n}=\frac{d}{2}$

$l_{n}=6 \mathrm{~mm}$

$l_{t}=\left(l_{w}-l_{n}-l_{n}\right) \times \mathrm{L}$

$l_{t}=90 m-6 m m-6 m m$

Karena w 1,5x dan a $63 \mathrm{x}$ maka didapat asumsi panjang langkah total adalah

$l_{t}=78 \mathrm{~mm} \times 94,5$ lang kah

$l_{t}=7371 \mathrm{~mm}$

$t_{c 1}=\frac{7371 \mathrm{~mm}}{1350 \mathrm{~mm} / \mathrm{min}}$

$t_{c 1}=6$ menit 29 detik

Karena pahat Ball nose Slot drill short diameter $12 \mathrm{~mm}$ ini di gunakan dalam 2 tahap maka $=12$ menit 58 detik

Karena w 2x dan a $63 x$ dan $1 / 3$ nya tidak terpotong, maka didapat asumsi panjang langkah total adalah

$l_{t}=78 \mathrm{~mm} \times 126$ lang kah $=9828 \mathrm{~mm}$

$l_{t}=6552 \mathrm{~mm}$

$t_{c 2}=\frac{6552 \mathrm{~mm}}{1350 \mathrm{~mm} / \mathrm{min}}$ 
$t_{c 2}=5$ menit 25 detik

Karena pahat Ball nose Slot drill short diameter $12 \mathrm{~mm}$ ini di gunakan dalam 2 tahap maka $=10$ menit 50 detik. Jadi waktu total pemakaian pahat Ball nose Slot drill short diameter $12 \mathrm{~mm}$ adalah 23 menit 48 detik.

4). Center drill diameter $2 \mathrm{~mm}$

$t_{c}=\frac{l_{t}}{v_{f}}$

$t_{c}=\frac{5 \mathrm{~mm}}{135 \mathrm{~mm} / \mathrm{min}}$

$t_{c}=0,03$ menit

5). Twist drill diameter $11,8 \mathrm{~mm}$

$t_{c}=\frac{l_{t}}{v_{f}}$

$t_{c}=\frac{20 \mathrm{~mm}}{334,8 \mathrm{~mm} / \mathrm{min}}$

$t_{c}=0,05$ menit

6). Reammer machbe diameter $12 \mathrm{H} 7$

$t_{c}=\frac{l_{t}}{v_{f}}$

$t_{c}=\frac{20 \mathrm{~mm}}{1350 \mathrm{~mm} / \mathrm{min}}$

$t_{c}=0,01$ menit

\section{d. Kecepatan penghasilan geram}

1). Slot drill short diameter $25 \mathrm{~mm}$ dengan jari-jari 0

$Z=\frac{v_{f} \cdot a \cdot w}{1000}$

$Z=\frac{2475 \mathrm{~mm} / \mathrm{min} \cdot 2,22 \mathrm{~mm} \cdot 12,5 \mathrm{~mm}}{1000}$

$Z=68,68 \mathrm{~cm}^{3} / \mathrm{min}$

2). Slot drill short diameter $10 \mathrm{~mm}$ dengan jari-jari $1 \mathrm{~mm}$

$Z=\frac{v_{f} \cdot a \cdot w}{1000}$

$Z=\frac{1200 \mathrm{~mm} / \min \cdot 0,5 \mathrm{~mm} \cdot 10 \mathrm{~mm}}{1000}$

$Z=6^{\mathrm{cm}^{3}} / \min$

3). Ball nose slot drill short diameter 12 $\mathrm{mm}$

$Z=\frac{v_{f} \cdot\left(l_{\alpha}-l_{s}\right)}{1000}$

$l_{\beta}=\beta_{a} / 360 \cdot \pi \cdot r^{2}$

$\cos \beta_{a}=t / r$

$\cos \beta_{a}=5,5 / 6$

$\beta_{a}=23,5^{0}$

$\beta=23,5^{0} \times 2=47,1^{0}$

$l_{\beta}=47,1 / 360 \cdot 3,14 \cdot(6 \mathrm{~mm})^{2}$
$=14,79 \mathrm{~mm}^{2}$

$l_{\Delta}=\frac{\text { alas } x \text { tinggi }}{2}$

alas $=2\left(\sqrt{(6 \mathrm{~mm})^{2-}(5,5 \mathrm{~mm})^{2}}\right)$

$=4,79 \mathrm{~mm}$

$l_{\Delta}=\frac{4,79 \mathrm{~mm} \times 5,5 \mathrm{~mm}}{2}$

$l_{\Delta}=13,1 \mathrm{~mm}^{2}$

$Z=\frac{1350 \mathrm{~mm} / \mathrm{min} \cdot\left(14,7 \mathrm{~mm}^{2}-13,1 \mathrm{~mm}^{2}\right)}{1000}$

$Z=2,28 \mathrm{~cm}^{3} / \mathrm{min}$

4). Center drill diameter $2 \mathrm{~mm}$

$Z=\frac{v_{f} \cdot \pi \cdot d^{2}}{4.1000}$

$Z=\frac{135 \mathrm{~mm} / \mathrm{min} \cdot 3,14 \cdot(2 \mathrm{~mm})^{2}}{4.1000}$

$Z=0,42 \mathrm{~cm}^{3} / \mathrm{min}$

5). Twist drill diameter $11,8 \mathrm{~mm}$

$Z=\frac{v_{f} \cdot \pi \cdot d^{2}}{4.1000}$

$Z=\frac{334,8 \mathrm{~mm} / \min ^{3} \cdot 3,14 \cdot(11,8 \mathrm{~mm})^{2}}{4.1000}$

$Z=36,5 \mathrm{~cm}^{3} / \min$

6). Reammer machbe diameter $12 \mathrm{H} 7$

$Z=\frac{v_{f} \cdot \pi \cdot d^{2}}{4.1000}$

$Z=\frac{1350 \mathrm{~mm} / \min \cdot 3,14 \cdot(12 \mathrm{~mm})^{2}}{4.1000}$

$Z=152,6 \mathrm{~cm}^{3} / \min$

\section{e. Gaya potong spesifik}

Gerakan dari setiap mata potong (gigi) pahat frais relatif terhadap benda kerja merupakan gerakan siklodial. Oleh sebab itu, bagaimanapun posisi pahat frais relatif terhadap lebar pemotongan atau kedalaman potong akan selalu memotong benda kerja dengan ketebalan geram yang berubah.gerak makan per gigi merupakan variabel yang penting dalam proses frais dan harganya ditentukan oleh kecepatan makan, putaran pahat, serta jumlah gigi.

1). Slot drill short diameter $25 \mathrm{~mm}$ dengan jari-jari 0

a) Tebal geram rata-rata pergigi

$f_{\text {zrata }^{2}}=\sin K_{r} \cdot \frac{360}{\pi} \cdot \frac{f_{z} \cdot w}{\varphi \cdot d}$

$\cos \varphi=\frac{d / 2-a r}{d / 2}$

$\cos \varphi=\frac{25 \mathrm{~mm} / 2-25}{25 \mathrm{~mm} / 2}$ 
$\varphi=180^{\circ}$

$f_{\text {zrata }^{2}}=\sin 90^{\circ} \cdot \frac{360^{0}}{3,14} \cdot \frac{0,165 \mathrm{~mm} / \mathrm{gigi} \cdot 12,5 \mathrm{~mm}}{180^{0} .25 \mathrm{~mm}}$

$f_{\text {zrata }^{2}}=0,105 \mathrm{~mm}$

b) Momen puntir rata rata

$M_{t m}=C_{1} \cdot d^{x} \cdot f_{\text {zrata }^{2}}^{y}$

$M_{t m}=$

$131 \mathrm{~N} / \mathrm{mm}^{2} \cdot(25 \mathrm{~mm})^{1,9} \cdot(0,105 \mathrm{~mm})^{0,83}$

$M_{t m}=9138,56 \mathrm{~N} \mathrm{~mm}$

c) Gaya potong spesifik rata-rata, dapat diicari dengan harga momen torsi ratarata :

$K_{s m}=\frac{2 \cdot \pi \cdot n \cdot M_{t m}}{w \cdot a \cdot v_{f}}$

$K_{\text {sm }}=\frac{2.3,14.7500 \mathrm{rpm} .9138,56 \mathrm{~N} \mathrm{~mm}}{12,5 \mathrm{~mm} .2,22 \mathrm{~mm} .2475 \mathrm{~mm} / \mathrm{min}}$

$K_{s m}=6267,01 \mathrm{~N} / \mathrm{mm}^{2}$

d) Gaya potong pergigi

$F_{t m}=A_{m} \cdot k_{s m}$

$A_{m}=2,22 \mathrm{~mm} \cdot 0,105 \mathrm{~mm}$

$A_{m}=0,23 \mathrm{~mm}^{2}$

$F_{t m}=0,23 \mathrm{~mm}^{2} \cdot 6267,01 \mathrm{~N} / \mathrm{mm}^{2}$

$F_{t m}=1441,4 \mathrm{~N}$

e) Jadi gaya tangensial total rata-rata adalah $1441,4 N \times 2=2882,8 N$

2). Slot drill short diameter $10 \mathrm{~mm}$ dengan jari-jari $1 \mathrm{~mm}$

a) Tebal geram rata-rata pergigi

$f_{\text {zrata }^{2}}=\sin K_{r} \cdot \frac{360}{\pi} \cdot \frac{f_{z} \cdot w}{\varphi \cdot d}$

$\cos \varphi=\frac{d / 2-a r}{d / 2}$

$\cos \varphi=\frac{10 \mathrm{~mm} / 2-10}{10 \mathrm{~mm} / 2}$

$\varphi=180^{\circ}$

$f_{\text {zrata }^{2}}=\sin 90^{\circ} \cdot \frac{360^{\circ}}{3,14} \cdot \frac{0,08 \mathrm{~mm} / \mathrm{gigi} \cdot 10 \mathrm{~mm}}{180^{\circ} \cdot 10 \mathrm{~mm}}$

$f_{\text {rata }^{2}}=0,05 \mathrm{~mm}$

b) Momen puntir rata rata

$M_{t m}=C_{1} \cdot d^{x} \cdot f_{z \text { rata }}^{y}$

$M_{t m}=131^{N} / \mathrm{mm}^{2} \cdot(10 \mathrm{~mm})^{1,9} \cdot(0,05 \mathrm{~mm})^{0,83}$

$M_{t m}=865,76 \mathrm{~N} \mathrm{~mm}$

c) Gaya potong spesifik rata-rata, dapat diicari dengan harga momen torsi ratarata :

$K_{s m}=\frac{2 \cdot \pi \cdot n \cdot M_{t m}}{w \cdot a \cdot v_{f}}$

$K_{\text {sm }}=\frac{2.3,14.7500 \mathrm{rpm} \cdot 865,76 \mathrm{~N} \mathrm{~mm}}{10 \mathrm{~mm} \cdot 0,5 \mathrm{~mm} \cdot 1200 \mathrm{~mm} / \mathrm{min}}$
$K_{s m}=6796,26 \mathrm{~N} / \mathrm{mm}^{2}$

d) Gaya tekan

$F=C_{2} \cdot d^{m} \cdot f^{n}$

$F=200 \mathrm{~N} / \mathrm{mm}^{2} \cdot(10 \mathrm{~mm})^{1,2} \cdot(0,1 \mathrm{~mm})^{1,1}$

$F=250 \mathrm{~N}$

e) Gaya potong pergigi

$F_{t m}=A_{m} \cdot k_{s m}$

$A_{m}=0,5 \mathrm{~mm} \cdot 0,05 \mathrm{~mm}$

$A_{m}=0,025 \mathrm{~mm}^{2}$

$F_{t m}=0,025 \mathrm{~mm}^{2} .6796,26 \mathrm{~N} / \mathrm{mm}^{2}$

$F_{t m}=169,9 \mathrm{~N}$

f) Jadi gaya tangensial total rata-rata adalah $F_{t m s}=F_{t m} \cdot z$

$169,9 N \times 2=339,81 N$

3). Ball nose Slot drill short diameter $12 \mathrm{~mm}$

a) Tebal geram rata-rata pergigi

$f_{z r a t a^{2}}=\sin K_{r} \cdot \frac{360}{\pi} \cdot \frac{f_{z} \cdot w}{\varphi \cdot d}$

$\cos \varphi=\frac{d / 2-a r}{d / 2}$

$\cos \varphi=\frac{4,4 \mathrm{~mm} / 2-4,4}{4,4 \mathrm{~mm} / 2}$

$\varphi=180^{\circ}$

$f_{\text {rata }^{2}}=\sin 90^{\circ} \cdot \frac{360^{\circ}}{3,14} \cdot \frac{0,09 \mathrm{~mm} / \mathrm{gigi}^{4} \cdot 4 \mathrm{~mm}}{180^{0} \cdot 4,4 \mathrm{~mm}}$

$f_{\text {zrata }^{2}}=0,057 \mathrm{~mm}$

b) Momen puntir rata rata

$M_{t m}=C_{1} \cdot d^{x} \cdot f_{z \text { rata }}^{y}$

$M_{t m}=131^{N} / \mathrm{mm}^{2} \cdot(12 \mathrm{~mm})^{1,9} \cdot(0,057 \mathrm{~mm})^{0,83}$

$M_{t m}=1364,66 \mathrm{~N} \mathrm{~mm}$

c) Gaya potong spesifik rata-rata, dapat diicari dengan harga momen torsi ratarata :

$k_{s m}=k_{s 1.1} h_{m}^{-p}$

$k_{s 1.1}=939 \sigma_{u}^{0,13}$

$k_{s 1.1}=939 .\left(525 \mathrm{~N} / \mathrm{mm}^{2}\right)^{0,13}$

$k_{s 1.1}=2119 \mathrm{~N} / \mathrm{mm}^{2}$

$k_{s m}=2119 \mathrm{~N} / \mathrm{mm}^{2}(0,057 \mathrm{~mm})^{-0,25}$

$k_{\text {sm }}=4336,7 \mathrm{~N} / \mathrm{mm}^{2}$

d) Gaya tekan

$F=C_{2} \cdot d^{m} \cdot f^{n}$

$F=200 \mathrm{~N} / \mathrm{mm}^{2} \cdot(12 \mathrm{~mm})^{1,2} \cdot(0,11 \mathrm{~mm})^{1,1}$

$F=315,6 N$

e) Gaya potong pergigi

$F_{t m}=A_{m} \cdot k_{s m}$

$A_{m}=0,5 \mathrm{~mm} \cdot 0,057 \mathrm{~mm}$

$A_{m}=0,025 \mathrm{~mm}^{2}$ 
$F_{t m}=0,025 \mathrm{~mm}^{2} .2119 \mathrm{~N} / \mathrm{mm}^{2}$

$F_{t m}=108,4 \mathrm{~N}$

f) Jadi gaya tangensial total rata-rata adalah $108,4 N \times 2=216,8 N$

4). Center drill diameter $2 \mathrm{~mm}$

a) Momen puntir

$M_{t m}=C_{1} \cdot d^{x} \cdot f^{y}$

$M_{t m}=131 \mathrm{~N} / \mathrm{mm}^{2} \cdot(2 \mathrm{~mm})^{1,9} \cdot(0,022 \mathrm{~mm})^{0,83}$

$M_{t m}=20,56 \mathrm{~N} \mathrm{~mm}$

b) Gaya tekan

$F=C_{2} \cdot d^{m} \cdot f^{n}$

$F=200 \mathrm{~N} / \mathrm{mm}^{2} \cdot(2 \mathrm{~mm})^{1,2} \cdot(0,011 \mathrm{~mm})^{1,1}$

$F=3,2 \mathrm{~N}$

c) Gaya potong spesifik, dapat dicari dengan harga momen puntir sebagai berikut :

$k_{d}=\frac{8 \cdot M_{t}}{d^{2} \cdot f}$

$k_{d}=\frac{8.20,56 \mathrm{~N} \mathrm{~mm}}{(2 \mathrm{~mm})^{2} .0,022 \mathrm{~mm}}$

$K_{d}=1869,09 \mathrm{~N} / \mathrm{mm}^{2}$

d) Jadi gaya tangensial pada mata potong pada senter drill adalah :

$k_{d}=\frac{F_{t}}{A}$

$A=\frac{d . f}{4}$

$A=\frac{2 m m \cdot 0,022 m m}{4}$

$A=0,011 \mathrm{~mm}^{2}$

$1869,09 \mathrm{~N} / \mathrm{mm}^{2}=\frac{F_{t}}{0,011 \mathrm{~mm}^{2}}$

$F_{t}=20,55 \mathrm{~N}$

5). Twist drill diameter $11,8 \mathrm{~mm}$

a) Momen puntir

$M_{t m}=C_{1} \cdot d^{x} \cdot f^{y}$

$M_{t m}=131^{N} / \mathrm{mm}^{2} \cdot(11,8 \mathrm{~mm})^{1,9} \cdot(0,062 \mathrm{~mm})^{0,83}$

$M_{t m}=1410,85 \mathrm{~N} \mathrm{~mm}$

b) Gaya tekan

$F=C_{2} \cdot d^{m} \cdot f^{n}$

$F=200 \mathrm{~N} / \mathrm{mm}^{2} \cdot(11,8 \mathrm{~mm})^{1,2} \cdot(0,124 \mathrm{~mm})^{1,1}$

$F=386,6 \mathrm{~N}$

c) Gaya potong spesifik, dapat diicari dengan harga momen torsi

$k_{d}=\frac{8 \cdot M_{t}}{d^{2} \cdot f}$

$k_{d}=\frac{8.1410,85 \mathrm{~N} \mathrm{~mm}}{(11,8 \mathrm{~mm})^{2} .0,124 \mathrm{~mm}}$

$K_{d}=653,71 \mathrm{~N} / \mathrm{mm}^{2}$

d) Jadi gaya tangensial pada mata potong pada senter drill adalah :
$k_{d}=\frac{F_{t}}{A}$

$A=\frac{d . f}{4}$

$A=\frac{11,8 \mathrm{~mm} \cdot 0,124 \mathrm{~mm}}{4}$

$A=0,365 \mathrm{~mm}^{2}$

$1152,22 \mathrm{~N} / \mathrm{mm}^{2}=\frac{F_{t}}{0,365 \mathrm{~mm}^{2}}$

$F_{t}=239,12 \mathrm{~N}$

6). Reammer machbe diameter $12 \mathrm{H} 7$

a) Momen puntir

$M_{t m}=C_{1} \cdot d^{x} \cdot f^{y}$

$M_{t m}=131 \mathrm{~N} / \mathrm{mm}^{2} \cdot(12 \mathrm{~mm})^{1,9} \cdot(0,09 \mathrm{~mm})^{0,83}$

$M_{t m}=1993,9 \mathrm{~N} \mathrm{~mm}$

b) Gaya tekan

$F=C_{2} \cdot d^{m} \cdot f^{n}$

$F=200 \mathrm{~N} / \mathrm{mm}^{2} \cdot(12 \mathrm{~mm})^{1,2} \cdot(0,18 \mathrm{~mm})^{1,1}$

$F=749,5 \mathrm{~N}$

c) Gaya potong spesifik, dapat diicari dengan harga momen torsi

$k_{d}=\frac{8 \cdot M_{t}}{d^{2} \cdot f}$

$k_{d}=\frac{8.1993,9 \mathrm{~N} \mathrm{~mm}}{(12 \mathrm{~mm})^{2} .0,09 \mathrm{~mm}}$

$K_{d}=1230,8^{\mathrm{N}} / \mathrm{mm}^{2}$

d) Jadi gaya tangensial pada mata potong pada senter drill adalah :

$k_{d}=\frac{F_{t}}{A}$

$A=\frac{d . f}{4}$

$A=\frac{12 \mathrm{~mm} \cdot 0,09 \mathrm{~mm}}{4}$

$A=0,27 \mathrm{~mm}^{2}$

$1152,22 \mathrm{~N} / \mathrm{mm}^{2}=\frac{F_{t}}{0,27 \mathrm{~mm}^{2}}$

$F_{t}=311,09 \mathrm{~N}$

\section{f. Daya dan efisiensi pemotongan}

Daya pemotongan dalam pembentukan geram ditentukan oleh gaya potong denggan kecepatan pemotongan (kecepatan pahat relatif terhadap benda kerja), atau momen puntir pada pahat dengan kecepatan putarnya.

Untuk milling, gaya pemotongan akan berfluktuasi sesuai dengan gaya tangensial atau momen puntir pada pahat milling. Oleh sebab itu diambil harga ratarata.

Efisiensi pemesinan berkisar dari $20 \%$ sampai $70 \%$, tergantung pada jenis proses dan kondisi pemotongan. Semakin 
berat kondisi pemotongan maka akan semakin tinggi efisiensi pemotongannya, begitu juga sebaliknya.

1). Slot Drill Short Diameter $25 \mathrm{~mm}$ JariJari 0

a) Daya pemesinan

$$
\begin{aligned}
& N_{\text {crata }^{2}}=\frac{M_{\text {trata }^{2}} \cdot \pi \cdot n}{60 \times 10^{6}} \\
& N_{\text {crata }}=\frac{9135,56 \mathrm{Nmm} .2 .3,14.7500 \mathrm{rpm}}{60 \times 10^{6}} \\
& N_{\text {crata }^{2}}=7,17 \mathrm{~kW}
\end{aligned}
$$

b) Efisiensi Pemesinan

$\eta_{c}=\frac{N_{c}}{N_{m c}} \times 100 \%$

$\eta_{c}=\frac{7,17 \mathrm{~kW}}{15 \mathrm{~kW}} \times 100 \%$

$\eta_{c}=47,5 \%$

2). Slot Drill Short Diameter $10 \mathrm{~mm}$ JariJari $1 \mathrm{~mm}$

a) Daya pemesinan

$$
\begin{aligned}
& N_{\text {crata }^{2}}=\frac{M_{t r a t a^{2}} \cdot \pi \cdot n}{60 \times 10^{6}} \\
& N_{\text {crata }}=\frac{865,76 \mathrm{Nm} \cdot 2.3,14.7500 \mathrm{rpm}}{60 \times 10^{6}} \\
& N_{\text {crata }^{2}}=0,67 \mathrm{~kW}
\end{aligned}
$$

b) Efisiensi Pemesinan

$\eta_{c}=\frac{N_{c}}{N_{m c}} \times 100 \%$

$\eta_{c}=\frac{0,67 \mathrm{~kW}}{15 \mathrm{~kW}} \times 100 \%$

$\eta_{c}=4,46 \%$

3). Ball Nose Slot Drill Short Diameter 12 $\mathrm{mm}$

a) Daya pemesinan

$$
\begin{aligned}
N_{c} & =\frac{F_{v} \cdot v}{60000} \\
N_{c} & =\frac{108,4 N .282,6 \mathrm{~m} / \mathrm{min}}{60000} \\
N_{c} & =0,5 \mathrm{~kW}
\end{aligned}
$$

b) Efisiensi Pemesinan

$$
\begin{aligned}
& \eta_{c}=\frac{N_{c}}{N_{m c}} \times 100 \% \\
& \eta_{c}=\frac{0,5 \mathrm{~kW}}{15 \mathrm{~kW}} \times 100 \% \\
& \eta_{c}=3,3 \%
\end{aligned}
$$

4). Center Drill Diameter $2 \mathrm{~mm}$

a) Daya pemesinan

$$
\begin{aligned}
& N_{\text {crata }}=\frac{M_{t r a t a}{ }^{2} \cdot \pi \cdot n}{60 \times 10^{6}} \\
& N_{\text {rrata }^{2}}=\frac{20,56 \mathrm{Nm} \cdot 2.3,14.4500 \mathrm{rpm}}{60 \times 10^{6}} \\
& N_{c \text { rata }}=0,0096 \mathrm{~kW} \\
& \text { b) Efisiensi Pemesinan } \\
& \eta_{c}=\frac{N_{c}}{N_{m c}} \times 100 \%
\end{aligned}
$$

$$
\begin{aligned}
& \eta_{c}=\frac{0,0096 \mathrm{~kW}}{15 \mathrm{~kW}} \times 100 \% \\
& \eta_{c}=0,06 \%
\end{aligned}
$$

5). Twist Drill Diameter $11,8 \mathrm{~mm}$

a) Daya pemesinan

$$
\begin{aligned}
& N_{\text {rrata }^{2}}=\frac{M_{\text {trata }^{2}} \cdot \pi \cdot n}{60 \times 10^{6}} \\
& N_{\text {rrata }^{2}}=\frac{2687,3 \mathrm{Nmm} .2 .3,14.2700 \mathrm{rpm}}{60 \times 10^{6}} \\
& N_{c \text { rata }}=0,75 \mathrm{~kW} \\
& \text { b) Efisiensi Pemesinan } \\
& \eta_{c}=\frac{N_{c}}{N_{m c}} \times 100 \% \\
& \eta_{c}=\frac{0,75 \mathrm{~kW}}{15 \mathrm{~kW}} \times 100 \% \\
& \eta_{c}=5,03 \%
\end{aligned}
$$

6). Reammer Machine Diameter $12 \mathrm{~mm} \mathrm{H7}$

a) Daya pemesinan

$$
\begin{aligned}
& N_{\text {crata }^{2}}=\frac{M_{\text {trata }^{2}} 2 \pi \cdot n}{60 \times 10^{6}} \\
& N_{\text {crata }^{2}}=\frac{1993,9 \mathrm{Nm} \cdot 2.3,14.7500 \mathrm{rpm}}{60 \times 10^{6}} \\
& N_{\text {crata }^{2}}=1,56 \mathrm{~kW}
\end{aligned}
$$

b) Efisiensi Pemesinan

$$
\begin{aligned}
\eta_{c} & =\frac{N_{c}}{N_{m c}} \times 100 \% \\
\eta_{c} & =\frac{1,56 \mathrm{~kW}}{15 \mathrm{~kW}} \times 100 \% \\
\eta_{c} & =10 \%
\end{aligned}
$$

\section{Pembahasan}

Berdasarkan data yang diperoleh dari perhitungan yang disajikan dalam tabel dan data dari pengamatan di lapangan, terjadi banyak perbedaan. Perbedaanperbedaan tersebut terjadi karena banyak faktor yang mempengaruhi, diantaranya adalah perbedaan sudut pandang antara penulis degan programer sebagai pembuat progran dan cutting servis sebagai acuan dari penggunaan cutter dan ketentuannya. Perbedaan-perbedaaan yang terjadi akan mempengaruhi setiap proses pemesinan. Dalam hal ini penulis mengambil data awal yang sama dengan programer yaitu dengan memanfaatkan putaran mesin sebesar $75 \%$ dengan menggunakan material dan cutter yang sama.

Perbedaan - perbedaan yang terjadi diawali dengan pengambilan gerak makan per gigi, dimana gerak makan per gigi akan mempengaruhi data - data yang lain. Karena gerak makan per gigi menjadi referensi untuk setiap proses pemesinan, semakin 
besar gerak makan pergigi maka akan semakin cepat suatu proses produksi.

Selain gerak makan pergigi, langkah pemesinan akan menjadi sangat penting karena semakin besar dept of cut nya pemesinan akan menjadi berat dan membutuhkan daya yang besar serta suara dan getaran yang terjadi sangat besar. Jika diambil dept of cut yang kecil akan berakibat peda panjangnya langkah pemesinan dan waktu yang ditempuh menjadi cukup lama serta efisiensi pemesinan yang berkurang.

Walaupun parameter dan hasil setiap perhitungan yang dilakukan penulis berbeda dengan perhitungan programer, waktu produksi yang dibutuhkan untuk menghasilkan part tersebut hampir sama hanya berbeda 3 menit dari proses pemesinan yang sebenarnya dan berbeda 3 menit dengan perhitungan yang dilakukan programer. Dengan efisiensi rata-rata pemesinan sebesar sebesar $13 \%$.

\section{Kesimpulan}

Waktu yang dibutuhkan untuk memproduksi part number D571-50081201, dari programmer untuk bidang satu dibutuhkan waktu sebesar 54 menit 21 detik dan bidang dua dibutuhkan waktu sebesar 46 menit 28 detik, sehingga total waktu pemesinan 100 menit 49 detik. Dari perhitungan penulis, bidang satu dibutuhkan waktu sebesar 56 menit 1 detik dan bidang dua dibutuhkan waktu sebesar 48 menit 8 detik, sehingga total waktu pemesinan 104 menit 9 detik.

Dari data lapangan, bidang satu dibutuhkan waktu sebesar 52 menit 30 detik dan bidang dua dibutuhkan waktu sebesar 56 menit 2 detik, dengan total waktu pemesinan 108 menit 32 detik

\section{Ucapan terimakasih}

Terimakasih untuk PT. Dirgantara Indonesia sebagai tempat penelitian dan pengambilan data.

\section{Referensi}

[1] Aisyati, A., Jauhari, W. A., \& Muhbiantie, R. T. (2012). Kebijakan
Persediaan Suku Cadang Pesawat Terbang untuk Mendukung Kegiatan Maintenance di PT GMF Aero Asia dengan Menggunakan Metode Continuous Review. In Seminar Sistem Produksi X,(hal. 1-7). Bandung.

[2] Wicaksono, S. (2016). Pengaruh Scanning Feed Pada Metode Reverse Engineering Terhadap Perbandingan Dimensi Camshaft Hasil Proses Manufaktur (Doctoral dissertation, Universitas Brawijaya).

[3] Adil, M. (2012). Pengembangan Industri Manufaktur Melalui Komputerisasi. Tekmapro: Journal of Industrial Engineering and Management, 2(1).

[4] Setyoadi, Y., \& Latifah, K. (2015). Integrasi Software CAD-CAM dalam Sistem Operasi Mesin Bubut CNC. Jurnal Informatika Upgris, 1(2 Desember).

[5] Faizal, A., Nababan, N. Y., \& Jatnika, M. E. (2020). Usulan Perbaikan Defect Pada Sablon Plastik Menggunakan Metode Poka Yoke Di CV. Bayor Print 69. Jurnal Ilmiah Teknologi Infomasi Terapan, 6(2), 167-175.

[6] Ahmad, Z. S. (2007). Pemodelan Dan Simulasi Proses Produksi PT Sermani Steel untuk Peningkatan Kapasitas Produksi dan Utilisasi Mesin (Doctoral dissertation, Institut Teknologi Sepuluh November).

[7] Surahto, A. Perbedaan Waktu Pengerjaan Pada Pemograman Incrementaldan Absolute Pada Mesin Cnc Milling Tu 3a. Jurnal Ilmiah Teknik Mesin Unisma" 45" Bekasi, 1(1), 97916.

[8] Ansyori, A. (2015). Pengaruh Kecepatan Potong dan Makan terhadap Umur Pahat pada Pemesinan Freis Paduan Magnesium. Mechanical, 6(1).

[9] Ivan, A. M., Coman, C. G., \& Nicolescu, A. F. (2016). Comparison Between Conventional Milling and 
Climb Milling in Robotic Deburring of Plastic Parts. Proceedings in Manufacturing Systems, 11(3), 165.

[10] Rochim, T. (2007). Proses Permesinan: Perkakas dan Sistem Pemerkakasan. Bandung: Penerbit ITB.

[11] Halliday, D., Resnick, R., \& Walker, J. (2013). Fundamentals of physics. John Wiley \& Sons.

[12] Amstead, B. H., Ostwald, P. E., \& Begeman, M. L. (1987). Manufacturing Processes, by John Wiley and Sons. INC., New York.

[13] Budiyanto, E., Setiawan, D. A., Supriadi, H., \& Ridhuan, K. (2017). Pengaruh Jarak Anoda-Katoda pada Proses Elektroplating Tembaga Terhadap Ketebalan Lapisan dan Efisiensi Katoda Baja AISI 1020. Turbo: Jurnal Program Studi Teknik Mesin, 5(1).

[14] Budiyanto, E., \& Yuono, L. D. (2018). Peranan Aerasi Sel Elektrolisis Dalam Pembentukan Pori pada Proses Anodizing Logam Aluminium. Turbo: Jurnal Program Studi Teknik Mesin, 7(2).

[15] Yuono, L. D., \& Budiyanto, E. (2020). Pengaruh perubahan sudut camshaft terhadap performa mesin sepeda motor sebagai upaya efisiensi energi. Turbo: Jurnal Program Studi Teknik Mesin, 9(1).

[16] Budiyanto, E., Nugroho, E., \& Masruri, A. (2017). Pengaruh diameter filler dan arus pada pengelasan TIG terhadap kekuatan tarik dan struktur mikro pada baja karbon rendah. Turbo: Jurnal Program Studi Teknik Mesin, 6(1).

[17] Budiyanto, E., Yuono, L. D., \& Farindra, A. (2019). Upaya Peningkatan Kualitas dan Kapasitas Produksi Mesin Pengupas Kulit Kopi Kering. Turbo: Jurnal Program Studi Teknik Mesin, 8(1). 